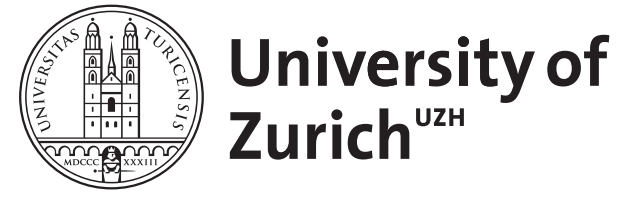

\title{
Reply to Agger and Kowalski
}

Holland, Steven M ; Reichenbach, Janine

DOI: https://doi.org/10.1086/651691

Posted at the Zurich Open Repository and Archive, University of Zurich ZORA URL: https://doi.org/10.5167/uzh-153974

Journal Article

Published Version

Originally published at:

Holland, Steven M; Reichenbach, Janine (2010). Reply to Agger and Kowalski. Clinical Infectious Diseases, 50(9):1325-1326.

DOI: https://doi.org/10.1086/651691 


\section{Correspondence}

\section{Chronic Granulomatous Disease, Catalase, and Actinomyces}

To THE EDITOR-We read with interest the article "Actinomyces in Chronic Granulomatous Disease: An Emerging and Unanticipated Pathogen" by Reichenbach et al [1]. However, we do not believe this series of patients with chronic granulomatous disease (CGD) and Actinomyces infection demonstrates compelling evidence to dismiss the traditionally recognized risk factor of microbial catalase as the most important virulence factor in patients with CGD unless phenotypic-negative catalase results from the species isolated in this series are made available.

Actinomyces infection in patients with CGD should not necessarily be considered as supporting evidence for a different mechanism of virulence, because $A c$ tinomyces species are not universally catalase negative, as was suggested in the article [1]. It is notable that, of the 8 Actinomyces isolates identified to the species level, 7 were identified as Actinomyces naeslundii (6 specimens had positive culture results, and 1 specimen had positive serological test results). The genospecies type 2 of A. naeslundii is catalase-positive in $~ 55 \%$ of isolates, and $30 \%$ of all genospecies isolates of $A$. naeslundii were catalase positive in one dental study [2]. Occasionally, other Actinomyces species can be catalase positive, as well [3]. In a recent review of 92 clinically significant strains of Actinomyces species identified by $16 \mathrm{~S}$ ribosomal DNA analysis, no isolates were identified as A. naeslundii, which highlighted the infrequency of this organism as a cause of clinically significant disease in patients without CGD [4].

Without this essential biochemical data, the conclusion that the "susceptibility of patients with CGD to infection with cat- alase-negative Actinomyces species confirms that catalase production is neither necessary nor sufficient for microbial virulence in CGD" is not supported by this article [1, pp 1708-1709]. Rather, catalase positivity, which is frequently found in $A$. naeslundii, may still explain most of these infections. In conclusion, this series may not significantly depart from the traditional association of catalase-positive microbial infections and CGD. Although catalase-negative infections in patients with CGD have been described, the frequency of such infections, compared with those due to catalase-producing organisms, and the importance of alternative mechanisms require further investigation.

\section{Acknowledgments}

Potential conflicts of interest. W.A.A. and T.J.K.: no conflicts.

William A. Agger and Todd J. Kowalski Gundersen Lutheran Medical Center

\section{References}

1. Reichenbach J, Lopatin U, Mahlaoui N, et al Actinomyces in chronic granulomatous disease: an emerging and unanticipated pathogen. Clin Infect Dis 2009; 49:1703-1710.

2. Tang G, Samaranayake LP, Yip HK. Genotypic diversity of oral Actinomyces naeslundii genospecies 1 and 2 in caries-active preschool children. Oral Microbiol Immunol 2004; 19: 371-378.

3. Winn W Jr, Allen S, Janda W, et al. Aerobic and facultative gram-positive bacilli. In: Koneman's color atlas and textbook of diagnostic microbiology. 6th ed. Baltimore, MD: Lippincott Williams \& Wilkins, 2006:818-819.

4. Clarridge JE III, Zhang Q. 2002. Genotypic diversity of clinical Actinomyces species: phenotype, source, and disease correlation among genospecies. J Clin Microbiol 2002; 40:34423448.

Reprints or correspondence: Dr William A. Agger, Gundersen Lutheran Medical Center, 1900 South Ave, La Crosse, Wisconsin 54601 (waagger@gundluth.org).

Clinical Infectious Diseases 2010;50(9):1325

(C) 2010 by the Infectious Diseases Society of America. All rights reserved. 1058-4838/2010/5009-0020\$15.00 DOl: 10.1086/651690

\section{Reply to Agger and Kowalski}

To тHE EDITOR-We appreciate the comments of Drs Agger and Kowalski, which echo the traditional assumption that microbial catalase production is the "most important virulence factor in patients with chronic granulomatous disease [CGD]" [1, p. 1325]. They rightly point out that Actinomyces can be variable in terms of catalase production, and although the majority of strains are catalase negative, a significant number may be catalase intermediate or even catalase positive. However, because Actinomyces are generally considered to be catalase negative, and because most are, we thought it important to point out that they do, in fact, cause significant morbidity in CGD. Although it is true that most pathogens associated with CGD are catalase positive, that is a general truism applicable to all pathogens that affect humans: most pathogens are catalase producing, with the broad exception of the streptococci. We cited several strong lines of clinical and basic evidence that support our assertion that catalase is not per se a necessary virulence factor in CGD infections. First, deletion of catalase from Staphylococcus aureus did not change its virulence in a mouse model of CGD [2]. Second, deletion of catalase from Aspergillus nidulans did not change its virulence in a mouse model of CGD [3]. Third, numerous case reports and cases from our current series are clearly caused by catalase negative organisms, negating catalase as a necessary virulence factor in CGD [4]. Drs Agger and Kowalski are correct that we did not study every strain of Actinomyces for catalase production, and there are indeed catalase-positive strains of Actinomyces naeslundii. We did study the National Institutes of Healthisolated strains for catalase production with use of standard techniques and found them (from patients 3, 4, 5, and 
8 [5]) to be catalase negative. Therefore-although the allure of the catalase hypothesis is strong, its directness of explanation is soothing, and it has longstanding prominence in the field-the clinical and laboratory evidence overwhelmingly indicates that catalase is neither necessary nor sufficient for virulence in CGD.

\section{Acknowledgments}

Potential conflicts of interest. S.M.H. and J.R.: no conflicts.

Steven M. Holland' and Janine Reichenbach ${ }^{2}$

'Laboratory of Clinical Infectious Diseases, National Institute for Allergy and Infectious Diseases, National Institutes of Health, Bethesda, Maryland; and ${ }^{2}$ Division of Immunology, Hematology, and Bone Marrow Transplantation, University Children's Hospital Zurich, Zurich, Switzerland

\section{References}

1. Agger WA, Kowalski TJ. Chronic granulomatous disease, catalase, and Actinomyces [letter]. Clin Infect Dis 2010; 50(9):1325 (in this issue).

2. Messina CG, Reeves EP, Roes J, Segal AW. Catalase negative Staphylococcus aureus retain virulence in mouse model of chronic granulomatous disease. FEBS Lett 2002; 518:107-110.

3. Chang YC, Segal BH, Holland SM, Miller GF, Kwon-Chung KJ. Virulence of catalase-deficient aspergillus nidulans in $\mathrm{p} 47$ (phox)-/- mice: implications for fungal pathogenicity and host defense in chronic granulomatous disease. J Clin Invest 1998; 101:1843-1850.

4. Kottilil S, Malech HL, Gill VJ, Holland SM. Infections with Haemophilus species in chronic granulomatous disease: insights into the interaction of bacterial catalase and $\mathrm{H} 2 \mathrm{O} 2$ production. Clin Immunol 2003; 106(3):226-230.

5. Reichenbach J, Lopatin U, Mahlaoui N, et al. Actinomyces in chronic granulomatous disease: an emerging and unanticipated pathogen. Clin Infect Dis 2009;49:1703-1710.

Reprints or correspondence: Dr Steven M. Holland, Laboratory of Clinical Infectious Diseases, National Institutes of Health, BIdg 10, CRC B3-4141, MSC 1684, Bethesda, Maryland 208921684 (sholland@niaid.nih.gov).

Clinical Infectious Diseases 2010;50(9):1325-1326 (C) 2010 by the Infectious Diseases Society of America. All rights reserved. 1058-4838/2010/5009-0021\$15.00 DOl: $10.1086 / 651691$

\section{Staphylococcal Toxic Shock Syndrome, Superantigenicity, and Hypersensitivity}

To THE EdiTor-With great interest, we read the article by Chandy et al [1] concerning staphylococcal toxic shock syn- drome (TSS) and its association with superantigenicity and hypersensitivity. The authors describe a 16-year-old girl who presented with severely acidotic hyperglycemia and concomitant Staphylococcus bacteremia, with accompanying TSS without rash or desquamation. Blood and urine cultures revealed methicillin-susceptible Staphylococcus aureus. The patient was treated with clindamycin for 5 days, cefazolin for 14 days, and immunoglobulin $(1 \mathrm{mg} / \mathrm{kg})$.

The authors state that $10 \%$ of S. aureus strains produce enterotoxin, but the prevalence of TSS is much lower than $10 \%$. Another explanation for this clinical picture is septic shock associated with community-acquired $S$. aureus bloodstream infection. Furthermore, the enterotoxin production could be an innocent bystander. Also, the patient did not meet the criteria for TSS because there was no rash or desquamation, but she did meet the criteria for community-acquired $S$. aureus bloodstream infection [2]. Given the limited clinical evidence for efficacy of immunoglobulin and clindamycin for the treatment of staphylococcal TSS, it seems unlikely that there was a causal relationship between the administration of clindamycin and immunoglobulin and the hemodynamic improvement after administration.

Therefore, we concluded that this patient had a complicated $S$. aureus bloodstream infection that was acquired in the community $[2,3]$. This infection has a high risk of hematogenous complications, and although there was no accompanying endocarditis, a recent review in this journal recommended at least 4 weeks of high-dose anti-staphylococcal penicillin for community-acquired $S$. aureus bloodstream infection $[2,3]$. The associated urine culture also grew S. aureus, and the patient had type 1 diabetes. Both factors are also associated with hematogenous complications and, possibly, provide an extra argument in favor of at least 4 weeks of high-dose therapy $[4,5]$.

\section{Acknowledgments}

Potential conflicts of interest. G.W.D.L. amd P.H.G.: no conflicts.

G. W. D. Landman ${ }^{1,2}$ and P. H. Groeneveld ${ }^{1}$ Internal Medicine and ${ }^{2}$ Diabetes Research Centre, Isala Clinics, Zwolle, the Netherlands

\section{References}

1. Chandy JC, Niermann M, Sharon B, et al. Staphylococcal toxic shock syndrome erythroderma is associated with superantigenicity and hypersensitivity. Clin Infect Dis 2009; 49: 1893-1894.

2. Fowler VG, Olsen MK, Corey GR, et al. Clinical identifiers of complicated Staphylococcus aureus bacteremia. Arch Intern Med 2003; 163:2066-2072.

3. Corey GR. Staphylococcus aureus bloodstream infections: definitions and treatment. Clin Infect Dis 2009; 48(suppl 4):S254-S259.

4. Pulcini C, Matta M, Mondain V, et al. Concomitant Staphylococcus aureus bacteriuria is associated with complicated $S$. aureus bacteremia. J Infect 2009; 59:240-246.

5. Fowler VG, Miro JM, Hoen B, et al. Staphylococcus aureus endocarditis: a consequence of medical progress. JAMA 2005; 293:3012-3021.

Reprints or correspondence: Dr G. W. D. Landman, Isala Clinics, PO Box 10400, 8000 GK Zwolle, the Netherlands (g.w.d.landman@isala.nl).

Clinical Infectious Diseases 2010;50(9):1326

(C) 2010 by the Infectious Diseases Society of America. All rights reserved. 1058-4838/2010/5009-0022\$15.00 DOl: $10.1086 / 651692$

\section{Reply to Landman and Groeneveld}

To THE Editors-We appreciate the interest of Landman and Groeneveld [1] in our study. They note that the child described in our article may have had septic shock due to community-associated Staphylococcus aureus infection rather than staphylococcal toxic shock syndrome (TSS). We cannot state definitively that the child had staphylococcal TSS, because all of the diagnostic criteria for staphylococcal TSS other than erythroderma and desquamation-the 2 criteria that the patient lacked-are common to both TSS and septic shock. It is also noteworthy that the presence of septic shock does not preclude the patient from having TSS. Although the majority of patients with staphylococcal TSS do not have blood cultures positive for $S$. aureus, a significant 